\title{
Low-Temperature Processing of Titanium Oxide Nanoparticles Photoanodes for Dye-Sensitized Solar Cells
}

\author{
Naji Al Dahoudi, ${ }^{1,2}$ Qifeng Zhang, ${ }^{1}$ and Guozhong Cao ${ }^{1}$ \\ ${ }^{1}$ Department of Materials Science and Engineering, University of Washington, Seattle, WA 98195, USA \\ ${ }^{2}$ Physics Department, Al Azhar University-Gaza, P.O. Box 1277, Gaza, Palestine \\ Correspondence should be addressed to Naji Al Dahoudi; naji@alazhar.edu.ps
}

Received 5 September 2012; Revised 20 October 2012; Accepted 26 October 2012

Academic Editor: Onder Ozgener

Copyright (c) 2013 Naji Al Dahoudi et al. This is an open access article distributed under the Creative Commons Attribution License, which permits unrestricted use, distribution, and reproduction in any medium, provided the original work is properly cited.

Using the low-temperature processing of different organofunctional silanes like TEOS, GPTS, and MPTS to incorporate within $\mathrm{TiO}_{2}$ network, dye-sensitized solar cells (DSCs) processed at low temperatures were obtained. The UV-cured MPTS-modified layer exhibited better performance over the TEOS and GPTS, where better mechanical stable layer is achieved in addition to better interconnection between the $\mathrm{TiO}_{2}$ nanoparticles. The $J-V$ characteristics of the DSC composed of silane-based layer showed that the improved cell performance was due to the high photocurrent density accompanied with more dye adsorption and higher charge injection from $\mathrm{TiO}_{2}$ to FTO substrate resulting from the formation of an ohmic contact with the substrate. The highest conversion efficiency attained for MPTS- $\mathrm{TiO}_{2}$ layer cured with UV and followed by heating at $300^{\circ} \mathrm{C}$ was $3.75 \pm 0.07 \%$, which is 2.8 times better than the GPTS-based layer.

\section{Introduction}

The increasing global demands of clean energy is becoming one of the major scientific challenges for scientists, economists, and politicians [1], as the combustion of fossil foils has produced widespread environmental damage [2]. Therefore, the Sun as an abundant source of energy represents the ideal source of clean energy, which has a solar flux deposited on the surface of the earth within one hour as much as the global power usage. However, the high production cost compared with the fossil foils has retarded the widespread commercialization of this alternative energy. There have been intensive investigations for higher efficiency and cost effective conversion of solar radiation to electricity.

Silicon-based solar cell technologies are currently the widely used commercial photovoltaic technology; however, the nonsilicon photovoltaic thin films are a major competitor with less cost and more flexibility than traditional solar cells [3]. One of the most promising technologies is the dyesensitized solar cells (DSCs), which have attracted much attention as they offer the possibility of extremely inexpensive and efficient solar energy conversion with flexible routes of production. The maximum reported efficiency since the first report published by O'Regan and Grätzel in 1991 [4], is with a current record of $\sim 11-13 \%$ [5-12]. DSC is a mimic of the photosynthesis and a physical separation between photon absorption and charge percolation process. The light is absorbed by a molecular dye, that is attached to the surface of semiconducting thick layer $(10-15 \mu \mathrm{m})$ deposited on transparent conducting oxide (TCO) electrode. The excited dye rapidly injects an electron into the semiconducting photoanode, where it diffuses through the sintered particle network to be collected through the TCO electrode, while the dye is regenerated via reduction by a redox shuttle electrolyte. The oxidized electrolyte is diffused to a counter electrode to complete the circuit. The recombination of the injected electron with the oxidized dye before it is regenerated, or the redox shuttle, can intercept an electron from the photoanode before it is collected, causing a drop on the total performance of the conversion process.

The intensive investigations of many researchers have been concentrated on three main components of the cell: the photoanode, the dye, and the electrolyte and/or the interfaces between them [12-14]. Conventional DSCs require to heat 
the photoanode at a temperature of $450^{\circ} \mathrm{C}$ or higher [15]. This annealing step is needed for ensuring good adherence of photoanode onto the substrate, eliminating the organic residues present in the paste or colloid, and improving the connection for efficient charge transport between the nanocrystallites that constitute the film. This step is difficult to be avoided and prevents the DSCs on flexible substrates that do not withstand high temperature annealing $[16,17]$. Different reports have been published to avoid the high temperature annealing of the thick photoanode layer, for example, by not using organic compounds in the formulation of the paste [18] or by using alternative way of sintering the nanoparticles via utilizing high mechanical pressure or curing them by electron beams or UV irradiation [19-21].

The inorganic-organic binders like Tetraethoxysilane (TEOS), 3-glycidoxypropyltrimethoxysilane (GPTS) or 3-methacryloxypropyltrimethoxysilane (MPTS), have also been used to enhance the electrical and mechanical properties of layers consisting of ITO nanoparticles $[22,23]$. The so-called organofunctional silanes are hybrid compounds that can be used as "molecular bridges" between inorganic materials. The advantages of such monomers include the fact that they can be readily polymerized at relatively low temperature, which allows them to be used for nanocomposite coatings that processed at low temperatures.

Recently, we have developed a DSC of multiporous structure by the modification of the $\mathrm{TiO}_{2}$ nanoparticles using MPTS, where a significant enhancement of the total performance of the cell was obtained [24]. In this study, we applied different silica coupling agents to coat $\mathrm{TiO}_{2}$ nanoparticles to further lower the processing temperature as a photoelectrode. Such coupling agents are aimed to have a cross linkage between titania nanoparticles at relatively low processing temperatures $\left(100-300^{\circ} \mathrm{C}\right)$. The microstructures, electrochemical properties, and the power conversion performance of the assembled DSCs composed of different silane networks, such as TEOS, GPTS, and MPTS, are compared and characterized.

\section{Experimental Work}

2.1. Photoelectrode Coating. Nanoparticles of $\mathrm{TiO}_{2}$ used in this work for preparing the coating paste were obtained by hydrothermally treating $\mathrm{TiO}_{2}$ sol, as previously reported [25]. Typically, $0.3 \mathrm{~g}$ of $\mathrm{TiO}_{2}$ powder is wetted and grinded by using $0.55 \mathrm{~g}$ of polyethylene Glycol solution (PEG400) in a mortar for 5 minutes. $0.05 \mathrm{~g}$ of $25 \mathrm{wt} \%$ ethanolic solution of Pluronic P123 and $0.1 \mathrm{~g}$ of $50 \mathrm{wt} \%$ ethanolic solution of hydrolyzed silane like TEOS, GPTS, and MPTS were added to the formed paste and further grinding for 5 minutes was applied to form a homogeneous viscous paste. The $\mathrm{TiO}_{2}$ paste was deposited onto FTO glass substrates using doctor blading technique to form a (12-14) $\pm 1 \mu \mathrm{m}$ thick film. The obtained films were cured by UV irradiation using a $4 \mathrm{~W}$ UV Mineralight multiband lamp (UV 254/365 nm, UVGL-25) for 10 hours, and finally the layers are heated at 120,200 , and $300^{\circ} \mathrm{C}$ for $3 \mathrm{~h}$ in air.
2.2. Cell Assembly and Characterization. The films were all sensitized by immersing them in $0.5 \mathrm{mM}$ ruthenium-based $\mathrm{N} 3$ dye solution for $24 \mathrm{~h}$, then rinsed in ethanol and dried in air at RT. A Pt-coated silicon substrate was used as the counter electrode, and an iodide-based solution, consisting of $0.6 \mathrm{M}$ tetrabutylammonium iodide, $0.1 \mathrm{M}$ lithium iodide, $0.1 \mathrm{M}$ iodine and $0.5 \mathrm{M}$ 4-tert-butylpyridine in acetonitrile, was used as the liquid electrolyte. Photovoltaic properties of each solar cell were characterized using simulated AM 1.5 sunlight illumination with an output power of $100 \mathrm{~mW} / \mathrm{cm}^{2}$. An Ultraviolet Solar Simulator (Model 16S, Solar Light Co., Philadelphia, PA) with a 200WXenon Lamp Power Supply (Model XPS 200, Solar Light Co., Philadelphia, PA) was used as the light source, and a Semiconductor Parameter Analyzer (4155A, Hewlett-Packard, Japan) was used to measure the current and voltage. The $I V$ measurements were repeated three times and the average results were reported. The electrochemical impedance spectroscopy (EIS) was carried out through the Solartron 1287A coupling with the Solartron $1260 \mathrm{FRA} /$ impedance analyzer to investigate electronic and ionic processes in DSCs.

Thermogravimetric analysis (TGA 7, Perkin-Elmer) was used to investigate the thermal behavior of the UV cured paste as a function of the annealing temperature.

X-ray Diffraction (XRD, Philips PW 1830 Diffractometer) was used to verify the phase and particle size of the $\mathrm{TiO}_{2}$ nanoparticle films. The morphology of the photoanode surfaces were characterized by scanning electron microscopy (SEM, JEOL JSM-7000). The BET surface area and the pore size distribution of the layers were determined by using Brunauer-Emmett-Teller (BET, Quantachrome NOVA 4200e).

To measure the adsorbed N3 dye amount on the silane modified $\mathrm{TiO}_{2}$ films, the dye was desorbed by immersing dye-sensitized films in a $0.1 \mathrm{M} \mathrm{NaOH}$ solution in water and ethanol $(1: 1, \mathrm{v} / \mathrm{v})$. An ultraviolet-visible-near infrared spectrophotometer (UV-VIS-NIR, Perkin Elmer Lambda 900) was employed to measure the dye concentration of the desorbed-dye solution.

\section{Results and Discussions}

3.1. DSCs Performance. The photovoltaic properties of the DSCs composed of silica and titania network were investigated for different types of hydrolyzed alkoxysilanes, such as TEOS, GPTS, and MPTS. The titania-TEOS layers formed at low temperatures up to $300^{\circ} \mathrm{C}$ were not stable and easily removed from substrates after the dye sensitization. The titania-GPTS layers were stable when the samples heated at temperatures greater than $180^{\circ} \mathrm{C}$, though the sample heated at $120^{\circ} \mathrm{C}$ was fragile after the dye sensitization. The titaniaMPTS layers were stable for all samples, which indicates the better cross-link gained by using the MPTS due to siloxanerich species especially after the UV polymerization that promote the condensation of the silanol groups [26]. Ukaji et al. [27] showed that the photo-catalytic activity and UVshielding ability were influenced by the number of surface 
TABLE 1: The DSC performance parameters for GPTS- and MPTS-modified $\mathrm{TiO}_{2}$ photoanode treated with UV curing and further annealing at different temperatures.

\begin{tabular}{lcccccrrr}
\hline & \multicolumn{2}{c}{$J_{\mathrm{sc}}\left(\mathrm{mA} / \mathrm{cm}^{2}\right)$} & \multicolumn{2}{c}{$V_{\text {oc }}(< \pm 0.01$ Volt $)$} & \multicolumn{2}{c}{$\eta(\%)$} & \multicolumn{2}{c}{ F.F. $(< \pm 0.01)$} \\
& MPTS & GPTS & MPTS & GPTS & MPTS & GPTS & MPTS & GPTS \\
\hline $120^{\circ} \mathrm{C}$ & $2.45 \pm 0.11$ & - & 0.692 & - & $1.17 \pm 0.04$ & - & 0.65 \\
$200^{\circ} \mathrm{C}$ & $6.35 \pm 0.13$ & $2.36 \pm 0.08$ & 0.703 & 0.71 & $2.86 \pm 0.05$ & $0.93 \pm 0.03$ & 0.62 \\
$300^{\circ} \mathrm{C}$ & $7.41 \pm 0.14$ & $3.21 \pm 0.15$ & 0.74 & 0.74 & $3.75 \pm 0.07$ & $1.34 \pm 0.06$ & 0.65 & 0.56 \\
\hline
\end{tabular}

groups of silane-modified $\mathrm{TiO}_{2}$ nanoparticles, which change the surface character of the modified sample.

The JV curves of the cells composed of the photoelectrodes treated at different temperatures for MPTS- and GPTS-modified titania samples are shown in Figures 1(a) and 1(b) and Table 1. No data is shown for all TEOS-titania samples and the GPTS-titania sample which treated at $120^{\circ} \mathrm{C}$, as part of the layer dissolved after the immersion of the dye solution. For the GPTS-modified sample (Figure 1(b)), it is exhibited that heating the photoanode layers from 200 to $300^{\circ} \mathrm{C}$ improved both the photocurrent density and the open circuit voltage with an increase of the efficiency from $0.93 \pm$ 0.03 to $1.34 \pm 0.06 \%$. Also a minimal increase of the filling factor was observed. On the other hand, the MPTS-modified sample attained an efficiency of $1.17 \pm 0.04 \%$, which is obtained even for the sample tempered at low temperature $\left(120^{\circ} \mathrm{C}\right)$. This means that MPTS may be considered as a suitable modifier for low-temperature processing, where silica network interconnects the titania nanoparticle forming an ohmic contact with the FTO substrate. Further improvement was obtained by further thermal treatment to $200^{\circ} \mathrm{C}$ and up to $300^{\circ} \mathrm{C}$, which is referred to the better contact between the titania nanoparticles, in addition to the reduction of the existence of the organics species that affect the dye loading. The conversion efficiency of the DSCs was improved considerably from $1.17 \pm 0.04 \%$ to $2.86 \pm 0.05 \%$ by raising the heating temperature from 120 to $200^{\circ} \mathrm{C}$. The main improvement of the efficiency was coming from the enhancement of the photocurrent density from $2.45 \pm 0.11$ to $6.35 \pm 0.13 \mathrm{~mA} / \mathrm{cm}^{2}$, while a minimal change of the open circuit voltage was observed. Further step of improvements was obtained by raising the heating temperature of the MPTS-titania photoelectrode layer up to $300^{\circ} \mathrm{C}$ due to an increase of the open circuit voltage by $37 \mathrm{mV}$ and a photocurrent density of $7.4 \pm$ $0.14 \mathrm{~mA} / \mathrm{cm}^{2}$ with an overall conversion efficiency of $3.75 \pm$ $0.07 \%$. This value is $64 \%$ greater than the efficiency of the bare titania nanoparticles heated at the same temperature [28]. Nguyen et al. [29] have reported that the enhanced performance of $\mathrm{TiO}_{2} / \mathrm{SiO}_{2}$ electrode over bare $\mathrm{TiO}_{2}$ one was ascribed to the role of $\mathrm{SiO}_{2}$ as an energy barrier, increasing the physical separation of injected electrons and oxidized dyes/redox couple, and thereby retarding the recombination reactions in the resulting DSC.

The superior performance results of MPTS over the TEOS- and GPTS-based layers might be referred to the fact that MPTS is a UV curable monomer much likely than GPTS and TEOS. From previous studies of using such monomers to interconnect tin-doped indium oxide (ITO) nanoparticles, it was found that MPTS allows the best cross linking of the conducting ITO nanoparticles under UV curing process [22]. The obtained sheet resistance of MPTS-ITO system was $8 \mathrm{~K} \Omega$, where those of GPTS- and TEOS-based system were 18 and $63 \mathrm{~K} \Omega$, respectively. The degree of polymerization as well as the cross linking of MPTS is enhanced by utilizing the UV irradiation as a result of the radical polymerization of the methacrylic moieties [30]. The thermal curing alone is not effective for the polymerization and the condensation process of the coatings. On the opposite, the UV treatment eliminates the $\mathrm{C}=\mathrm{C}$ band, strongly reduces the $\mathrm{C}=\mathrm{O}$ band, and forms a well-defined $\mathrm{Si}-\mathrm{O}-\mathrm{Si}$ network linking homogeneously the particles together. The epoxy group in the GPTS could react with water to form glycol, which may terminate the polymerization of the monomer [31].

The main characteristic of the enhancement of the conversion efficiency of MPTS-titania layer is attributed to the improvements of the photocurrent density, which is mainly referred to the difference of the dye adsorption as shown in Figure 3. The removal of the organic species from the films allowed more dye to penetrate the bulk of the thick film, where the texture of the heated films was changed accordingly. The TGA results shown in Figure 2 exhibited a significant weight loss for UV-treated $\mathrm{MPTS}-\mathrm{TiO}_{2}$ sample compared with that of GPTS-TiO $\mathrm{T}_{2}$ system. Larger surface area and pore size have a strong influence on the dye adsorption. It is thought that the silica network interconnected the $\mathrm{TiO}_{2}$ nanoparticles, which enhances the electron path within the photoanode layer. It is noticeable that the outperformance of the hydrolyzed MPTS over the other silica coupling agents may refer to its capability of long chain polymerization after the UV treatment, which allows direct pathway for the electron transport.

3.2. Thermal Analysis. The TGA curve shown in Figure 2 belongs to the GPTS- and MPTS-based Titania paste after $10 \mathrm{~h} \mathrm{UV}$ curing and drying overnight at $80^{\circ} \mathrm{C}$. The curve of the GPTS-titania sample showed a slower weight loss compared with MPTS-titania sample. The sample exhibited three distinct steps. The first stage is due to the removal of the physically adsorbed water up to $100^{\circ} \mathrm{C}$. The second stage is up to $250^{\circ} \mathrm{C}$, which is attributed to the release of the surfactant and the polyethylene glycol. The third stage is between 250 and $350^{\circ} \mathrm{C}$, which is due to the condensation of the silica network. The degradation of the organic species in the paste of MPTS-titania exhibited a continuous weight loss of $4.5 \%$, $21 \%$, and $55 \%$ at the working temperatures 120,200 , and $300^{\circ} \mathrm{C}$. Contrary to the GPTS-titania paste, no significant 


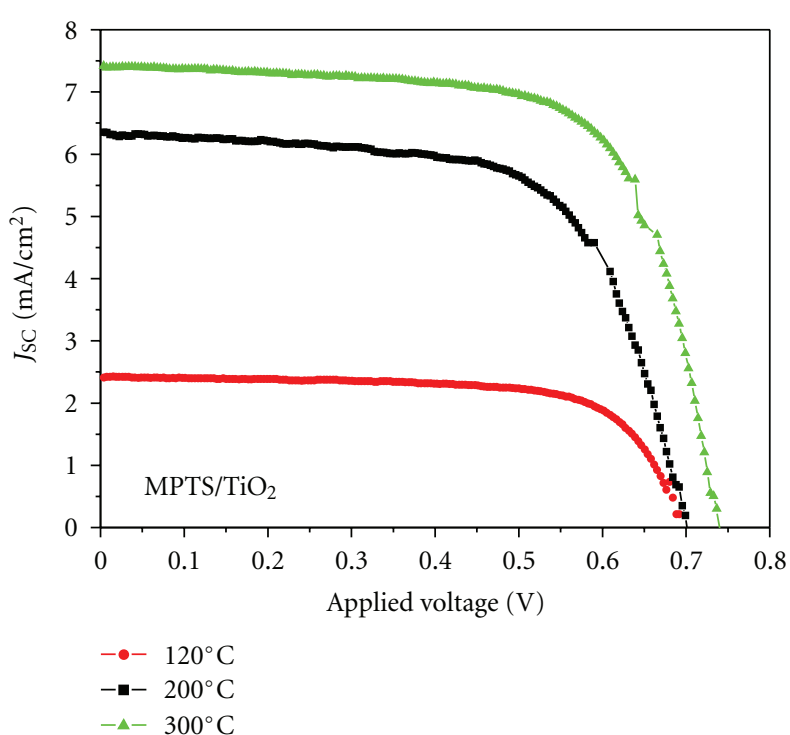

(a)

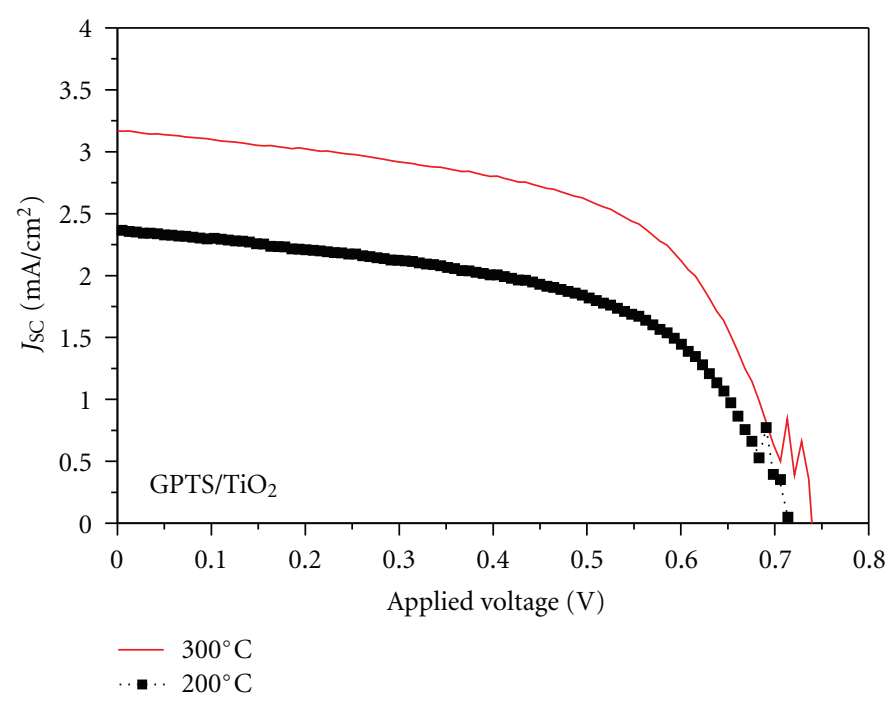

(b)

FIGURE 1: The $J V$ curves for DSCs composed of MPTS- $\mathrm{TiO}_{2}$ electrode (a) and GPTS- $\mathrm{TiO}_{2}$ one (b) treated with UV curing and further annealing at different temperatures.

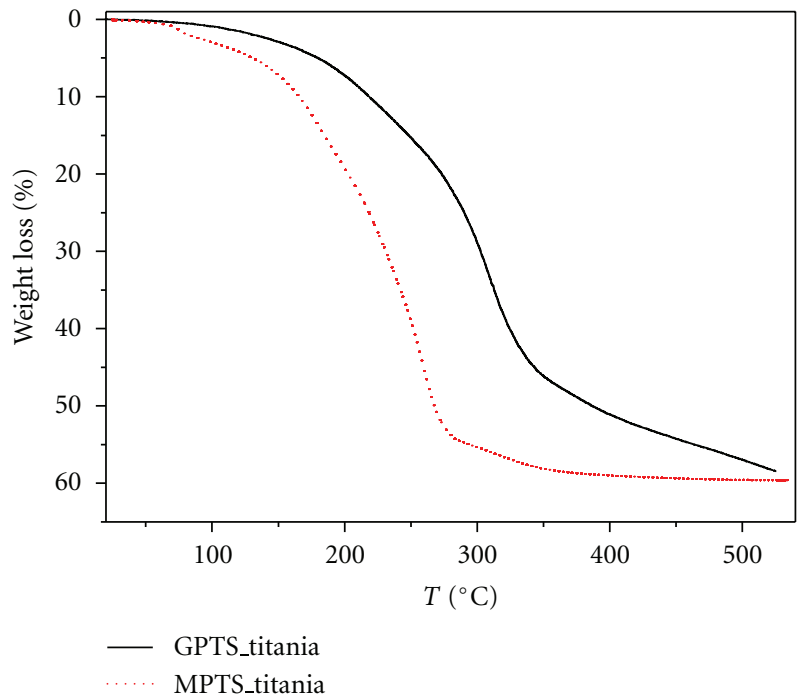

Figure 2: TGA for GPTS- and MPTS-modified $\mathrm{TiO}_{2}$ samples.

weight loss for the MPTS-titania sample was observed at temperature higher than $300^{\circ} \mathrm{C}$, which means that most of the hydrogel network can be removed at relatively low processing temperature. The UV irradiation of the $\mathrm{TiO}_{2}$ paste may be resulted in a degradation of the organic groups, where it is common to use titanium oxide as a mean to degrade the organic wastes $[32,33]$.

3.3. Dye Loading. The amount of the dye loaded on the heattreated MPTS-titania photoelectrode films were determined using UV-Vis spectroscopy. The dye N719 was first detached from the layers using $5 \mathrm{~mL} 0.1 \mathrm{mM} \mathrm{KOH}$ solution. Figure 3

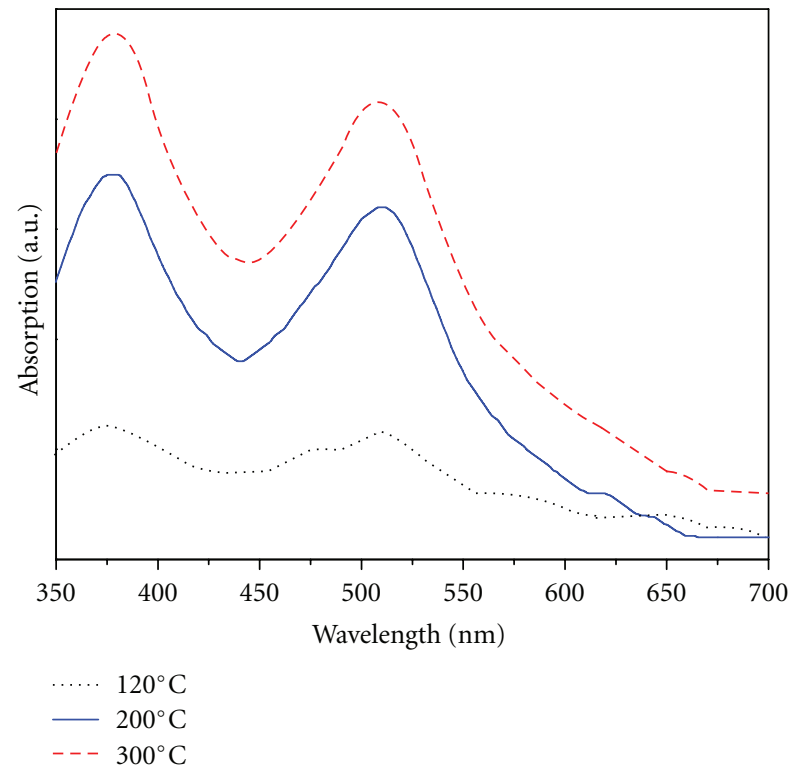

FIGURE 3: The UV-VIS absorption of the deattached dye from $\mathrm{MPTS} / \mathrm{TiO}_{2}$ layers treated with UV curing and further annealing at different temperatures.

shows that the sample absorption of the detached dye increases by increasing the heat treatment temperature. Based on the experimental data shown in the UV-Vis absorption spectra, the amounts of dye loaded on each layer is estimated to be $2.75 \times 10^{-8}, 6.53 \times 10^{-8}$, and $9.21 \times 10^{-8} \mathrm{~mol} / \mathrm{cm}^{2}$ for the samples treated at 120,200 , and $300^{\circ} \mathrm{C}$, respectively. The amount of the dye loaded for the GPTS-titania sample heated at $300^{\circ} \mathrm{C}$ was $3.2 \times 10^{-8} \mathrm{~mol} / \mathrm{cm}^{2}$. The amount of 
TABLE 2: BET results for the MPTS-based $\mathrm{TiO}_{2}$ photoelectrodes annealed at the different temperatures.

\begin{tabular}{lccc}
\hline Sample & $\begin{array}{c}\text { Surface area } \\
\left(\mathrm{m}^{2} / \mathrm{g}\right)\end{array}$ & $\begin{array}{c}\text { Pore volume } \\
(\mathrm{cc} / \mathrm{g})\end{array}$ & $\begin{array}{c}\text { Pore size } \\
(\mathrm{nm})\end{array}$ \\
\hline $120^{\circ} \mathrm{C}$ & 32.6 & 0.38 & 2.1 \\
$200^{\circ} \mathrm{C}$ & 56.2 & 0.35 & 2.9 \\
$300^{\circ} \mathrm{C}$ & 70.1 & 0.33 & 3.2 \\
\hline
\end{tabular}

the dye loaded on the layers is an indication that the porous structure obviously improved the absorption of dye because of its large surface areas as shown in Table 2. The significant improvement in dye loading could result in a better light harvesting and a higher photocurrent conversion efficiency of the device, which is obvious from the results in Table 1.

3.4. BET Surface Area. The heat treatment temperature strongly influences the texture properties of the MPTS$\mathrm{TiO}_{2}$ electrodes, which were investigated by $\mathrm{N}_{2}$ adsorption measurements. The resulting adsorption and desorption isotherms for the different heat-treated MPTS-based samples exhibited a hysteresis loop with type IV isotherms with a sharp capillary condensation step at high relative pressures $(P / P o=0.8-0.9)$ as shown in Figure 4 . The surface area, pore volume, and average pore diameter were calculated by the BET method and the results are given in Table 2. An increase of the BET surface area from 32.6 to 56 and then to $70 \mathrm{~m}^{2} / \mathrm{g}$ was observed when the heating temperature was raised from 120 to 200 and then to $300^{\circ} \mathrm{C}$, respectively. A relative increase of the pore size was calculated (Table 2) corresponding to the increase of the heating temperature, which indicates a removal of organic species of the binder. The increase of the surface area and the pore size might well explain the increased amount of dye loaded as revealed in Figure 3.

\subsection{Structural Properties}

3.5.1. XRD. The diffraction patterns of the $\mathrm{MPTS}^{-\mathrm{TiO}_{2}}$ nanoparticulate layers deposited on FTO glass substrate, UV cured in addition heating at 120,200 , and $300^{\circ} \mathrm{C}$ are shown in Figure 5. All peaks correspond to Anatase phase, like the original nanopowder [25]. No existence for other phases were detected, and almost no change in the crystallite size was observed at the different heating temperature.

3.6. Surface Morphology. The SEM surface morphologies with different magnification of the prepared MPTS- $\mathrm{TiO}_{2}$ electrodes heated at 120,200 , and $300^{\circ} \mathrm{C}$ are shown in Figures 6(a), 6(b), and 6(c), respectively. As shown in Figure 6(a), the sample treated at $120^{\circ} \mathrm{C}$ showed homogeneous surface with obvious loosely packed aggregates dispersed in organic matrix. The 200 and $300^{\circ} \mathrm{C}$ treated samples showed sharper morphology and closely packed aggregates were formed; however, a closer inspection revealed that the $\mathrm{TiO}_{2}$ film treated at higher temperature had indeed multiporous structure made up of nanocrystalline titanium dioxide particles. The $300^{\circ} \mathrm{C}$ treated sample showed larger porous structure.

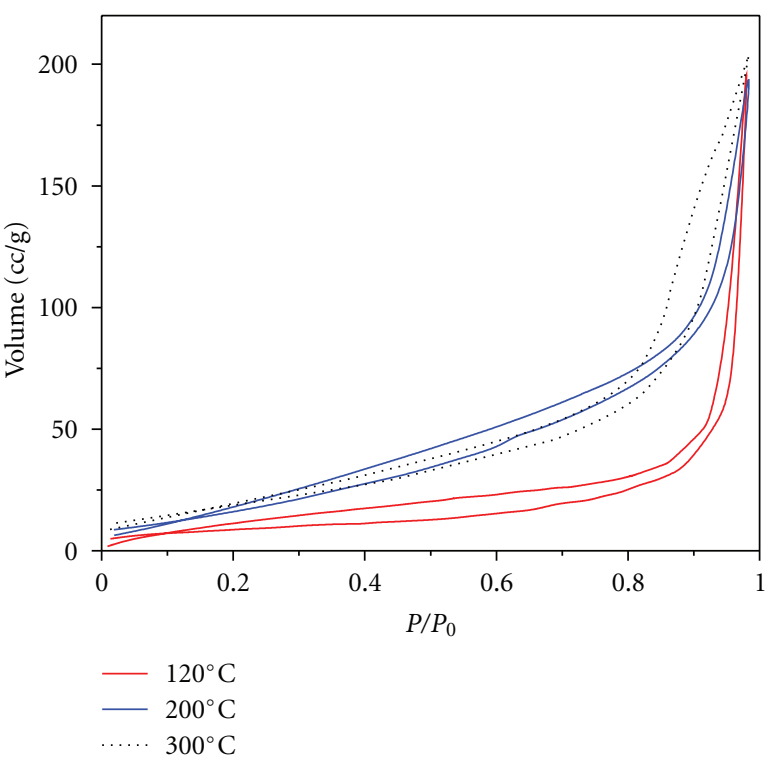

FIGURE 4: Adsorption-desorption isotherm using $\mathrm{N}_{2}$ at $77 \mathrm{~K}$ for $\mathrm{MPTS} / \mathrm{TiO}_{2}$ samples cured with UV an further annealing at different temperatures.

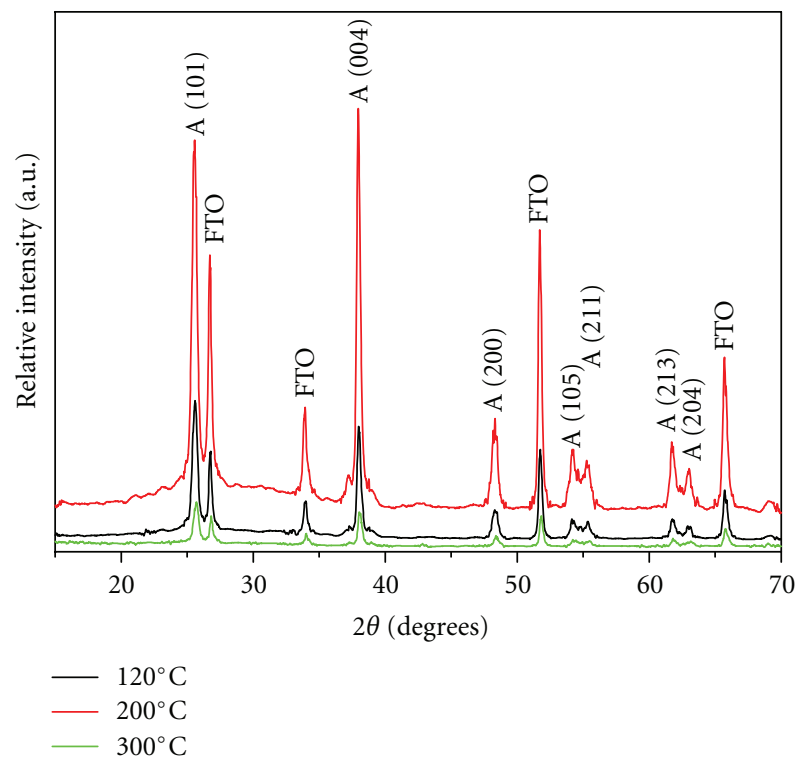

FIGURE 5: XRD patterns of MPTS- $\mathrm{TiO}_{2}$ nanoparticulate films on FTO substrates after UV curing and further heating at 120, 200 and $300^{\circ} \mathrm{C}$.

These multiporous structures resulted from the decomposition of organic binder, which could be expected to have a larger surface area and more convenient dye loading as well as more electrolyte transportation.

3.7. Electrochemical Impedance Spectroscopy. The impedance data measured at the open-circuit voltage under dark condition with electrochemical impedance spectroscopy (EIS) was utilized to determine the charge-transfer resistance between the transparent-conducting oxide (FTO) and the $\mathrm{TiO}_{2}$ porous 

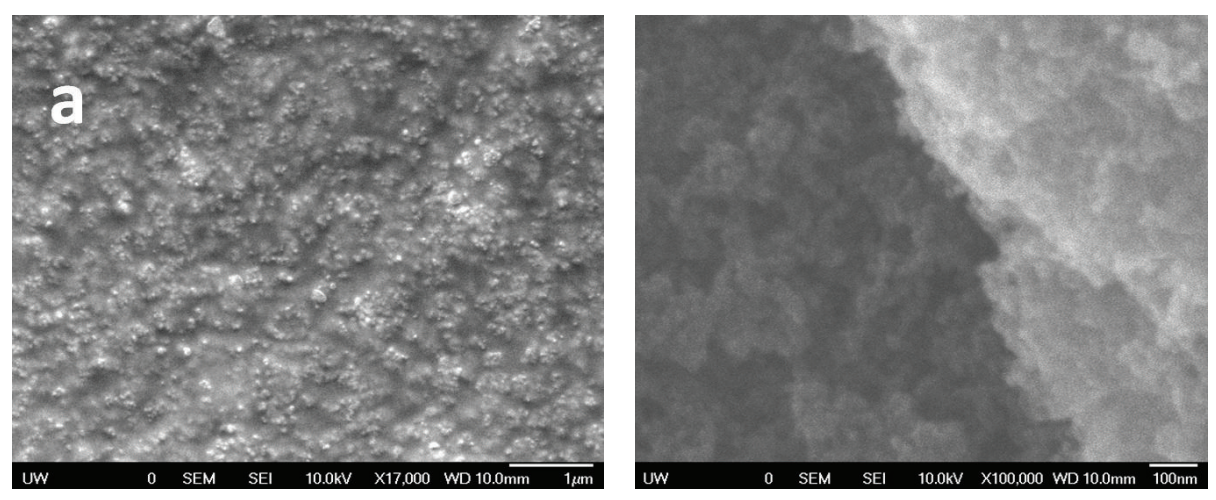

(a)
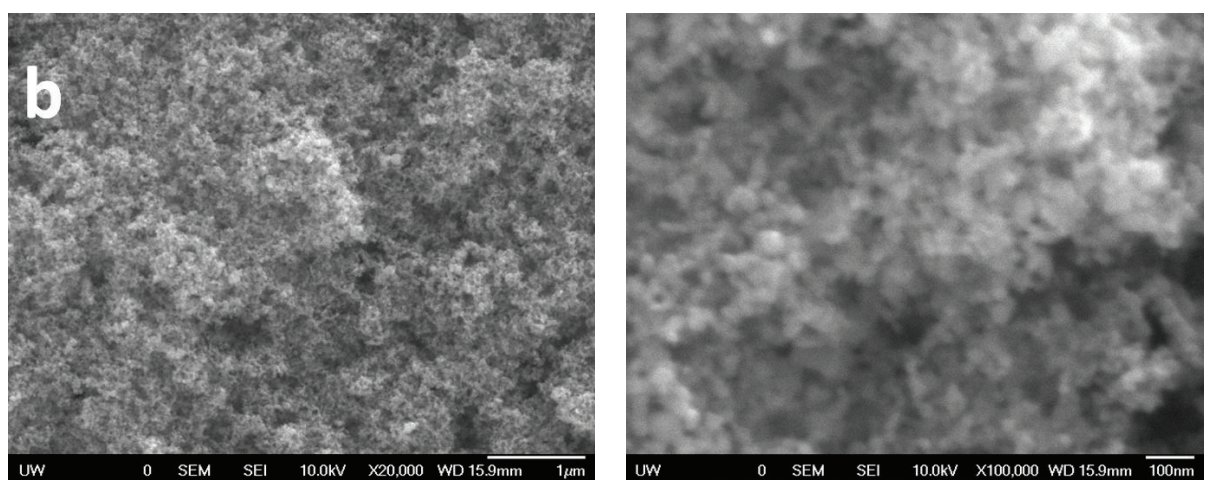

(b)
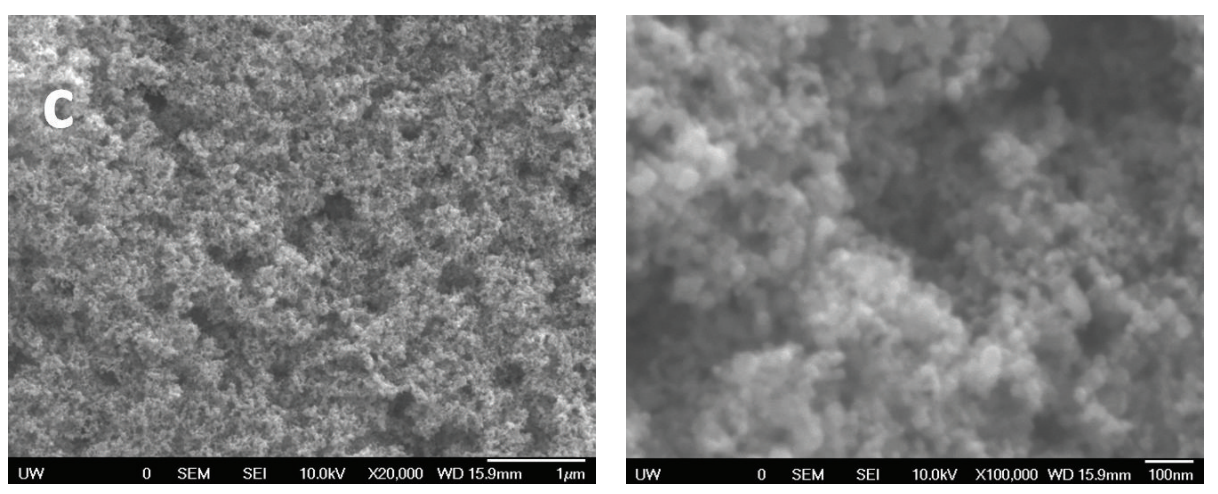

(c)

FIGURE 6: SEM images of porous MPTS modified $\mathrm{TiO}_{2}$ films produced by curing them using UV irradiation and further annealing at (a) $120^{\circ} \mathrm{C}$, (b) $200^{\circ} \mathrm{C}$, and (c) $300^{\circ} \mathrm{C}$.

layer and the interface between $\mathrm{TiO}_{2}$ /dye/electrolyte, as shown in Figure 7. The measured frequency range was from $0.1 \mathrm{~Hz}$ to $100 \mathrm{kHz}$. Usually, the impedance plot of a DSC exhibits two semicircles or arcs in the Nyquist diagram $[34,35]$. The first semicircle in the high-frequency region is attributed to the impedance of the charge transfer process at the counter electrode. The second semicircle in the middlefrequency region is related to the charge-transfer process at the $\mathrm{TiO}_{2}$ /dye/electrolyte interface as well as the resistance to the transport of electrons to the working electrode. The impedance data is interpreted using equivalent electrical circuit elements as shown in the inset of Figure 7 . In this study, the charge transfer resistance $\left(R_{\mathrm{ct}}\right)$ increased from
$71 \pm 6 \Omega$ to $144 \pm 5 \Omega$ when the annealing temperature increased from $120^{\circ} \mathrm{C}$ to $200^{\circ} \mathrm{C}$ and a reduction to $126 \pm$ $9 \Omega$ by further increase to $300^{\circ} \mathrm{C}$. This reveals that the lowtemperature sample suffered from a high charge combination rate due to the existence of some organic residues that were present in the photoanode. This may be due to the decrease in pore size of the $\mathrm{TiO}_{2}$ film and thus decreasing the dye adsorption as well as penetration of redox couples into the pores of $\mathrm{TiO}_{2}$ electrode. Correspondingly, the characteristic frequency peaks shifted to lower frequency when the heating temperature increased to $200^{\circ} \mathrm{C}$ and then shifted slightly back again to higher frequency when the heating temperature was raised to $300^{\circ} \mathrm{C}$. The characteristic frequency is related to 


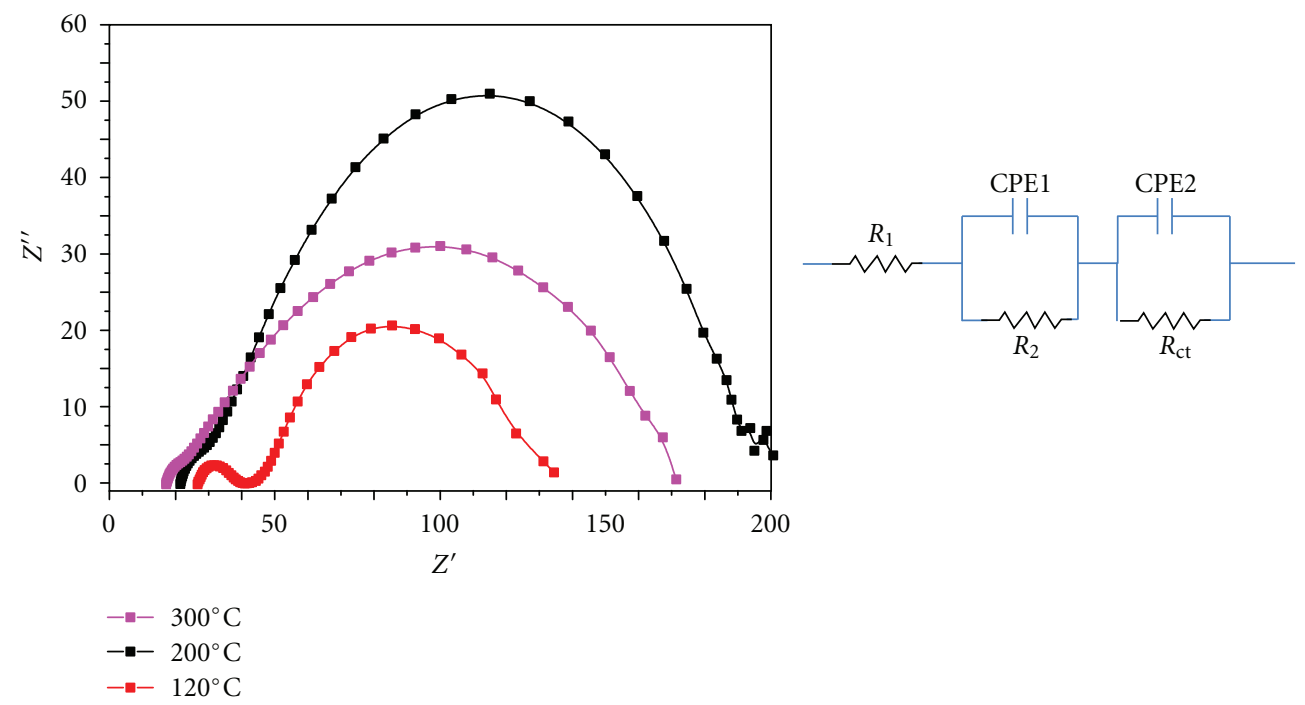

FIGURE 7: EIS spectra showing Nyquist plots of the $\mathrm{MPTS} / \mathrm{TiO}_{2}$ DSC annealed at different temperatures after UV irradiation. The inset shows the equivalent circuit.

the inverse of the recombination lifetime $\left(\tau_{r}\right)$ or electron lifetime $\left(\tau_{e}\right)$ in the $\mathrm{TiO}_{2}$ film [36]. The increase of the recombination rate of the $300^{\circ} \mathrm{C}$ sample might be attributed to more and easy electrolyte penetration due to high mesoporous surface area, large porosity, and large pores, which makes the recombination centers closer to the $\mathrm{TiO}_{2}$ surfaces. The Ohmic serial resistance $\left(R_{1}\right)$ corresponds to the overall series resistance decreased gradually by raising the heating temperature from 120 to $300^{\circ} \mathrm{C}$. Such decrease is expected due to better interconnection between the $\mathrm{TiO}_{2}$ nanoparticles, which results in the improvement of the electron path and consequently higher photocurrent density will be observed.

\section{Conclusions}

Among three silane coupling agents investigated, MPTS shows a great promise for low-temperature processing of $\mathrm{TiO}_{2}$ photoanodes for DSCs. The $J-V$ characteristics of the DSC composed of MPTS-based layer showed that the improved cell performance was due to the high photocurrent density facilitated with more dye adsorption and higher charge injection from $\mathrm{TiO}_{2}$ to FTO substrate resulting from the formation of an Ohmic contact with the substrate. The conversion efficiency attained for $\mathrm{MPTS}-\mathrm{TiO}_{2}$ layer cured with UV and followed by heating at $200^{\circ} \mathrm{C}$ was $2.86 \pm 0.05 \%$, where further heating at $300^{\circ} \mathrm{C}$ raised the power conversion efficiency to $3.75 \pm 0.07 \%$.

\section{Acknowledgments}

N. Al Dahoudi would like to acknowledge the Council for International Exchange of Scholars (CIES) for their Fulbright Scholarship. Also, this work has been supported in part by the US Department of Energy, Office of Basic Energy Sciences, Division of Materials and Engineering under Award no. DE-FG02-07ER46467 (Q.F.Z.) on the microstructure characterization and some power conversion efficiency measurements, National Science Foundation (DMR-1035196), Boeing-Steiner Endowment, University of Washington TGIF, grant, and Intel Corporation.

\section{References}

[1] G. W. Crabtree and N. S. Lewis, "Solar energy conversion," Physics Today, vol. 60, no. 3, pp. 37-42, 2007.

[2] R. A. Kerr, "How urgent is climate change?" Science, vol. 318, no. 5854, pp. 1230-1231, 2007.

[3] R. D. McConnell, "Assessment of the dye-sensitized solar cell," Renewable and Sustainable Energy Reviews, vol. 6, no. 3, pp. 273-295, 2002.

[4] B. O’Regan and M. Grätzel, "A low-cost, high-efficiency solar cell based on dye-sensitized colloidal $\mathrm{TiO}_{2}$ films," Nature, vol. 353, no. 6346, pp. 737-740, 1991.

[5] Y. Chiba, A. Islam, Y. Watanabe, R. Komiya, N. Koide, and L. Han, "Dye-sensitized solar cells with conversion efficiency of 11.1\%," Japanese Journal of Applied Physics, vol. 45, no. 24-28, pp. L638-L640, 2006.

[6] M. K. Nazeeruddin, F. De Angelis, S. Fantacci et al., "Combined experimental and DFT-TDDFT computational study of photoelectrochemical cell ruthenium sensitizers," Journal of the American Chemical Society, vol. 127, no. 48, pp. 16835-16847, 2005.

[7] M. Grätzel, "Solar energy conversion by dye-sensitized photovoltaic cells," Inorganic Chemistry, vol. 44, no. 20, pp. 6841-6851, 2005.

[8] M. Grätzel, "Dye-sensitized solid-state heterojunction solar cells," MRS Bulletin, vol. 30, no. 1, pp. 23-27, 2005.

[9] Y. Chiba, A. Islam, R. Komiya, N. Koide, and L. Han, "Conversion efficiency of $10.8 \%$ by a dye-sensitized solar cell using a $\mathrm{TiO}_{2}$ electrode with high haze," Applied Physics Letters, vol. 88, no. 22, Article ID 223505, 2006. 
[10] Z. S. Wang, M. Yanagida, K. Sayama, and H. Sugihara, "Electronic-insulating coating of $\mathrm{CaCO}_{3}$ on $\mathrm{TiO}_{2}$ electrode in dyesensitized solar cells: improvement of electron lifetime and efficiency," Chemistry of Materials, vol. 18, no. 12, pp. 2912-2916, 2006.

[11] M. K. Nazeeruddin, E. Baranoff, and M. Grätzel, "Dyesensitized solar cells: a brief overview," Solar Energy, vol. 85, no. 6, pp. 1172-1178, 2011.

[12] A. Yella, H. W. Lee, H. N. Tsao et al., "Porphyrin-sensitized solar cells with cobalt (II/III)-based redox electrolyte exceed 12 percent efficiency," Science, vol. 334, no. 6056, pp. 629-634, 2011.

[13] S.-H. Fan, A.-G. Zhang, C. C. Ju, and K.-Z. Wang, "A phenylcarbazole functionalized ruthenium dye for efficient dye-sensitized solar cells," Solar Energy, vol. 85, no. 10, pp. 2497-2506, 2011.

[14] L. Guo, X. Pan, C. Zhang et al., "Ionic liquid electrolyte based on S-propyltetrahydrothiophenium iodide for dye-sensitized solar cells," Solar Energy, vol. 84, no. 3, pp. 373-378, 2010.

[15] D. Zhao, T. Peng, L. Lu, P. Cai, P. Jiang, and Z. Bian, "Effect of annealing temperature on the photoelectrochemical properties of dye-sensitized solar cells made with mesoporous $\mathrm{TiO}_{2}$ nanoparticles," Journal of Physical Chemistry C, vol. 112, no. 22, pp. 8486-8494, 2008.

[16] B. Wang and L. L. Kerr, "Dye sensitized solar cells on paper substrates," Solar Energy Materials and Solar Cells, vol. 95, no. 8, pp. 2531-2535, 2011.

[17] S.-S. Kim, J. H. Yum, and Y. E. Sung, "Flexible dye-sensitized solar cells using $\mathrm{ZnO}$ coated $\mathrm{TiO}_{2}$ nanoparticles," Journal of Photochemistry and Photobiology A, vol. 171, no. 3, pp. 269-273, 2005.

[18] F. Pichot, J. R. Pitts, and B. A. Gregg, "Low-temperature sintering of $\mathrm{TiO}_{2}$ colloids: application to flexible dye-sensitized solar cells," Langmuir, vol. 16, no. 13, pp. 5626-5630, 2000.

[19] T. Kado, M. Yamaguchi, Y. Yamada, and S. Hayase, "Low temperature preparation of nano-porous $\mathrm{TiO}_{2}$ layers for plastic dye sensitized solar cells," Chemistry Letters, vol. 32, no. 11, pp. 1056-1057, 2003.

[20] D. Gutiérrez-Tauste, I. Zumeta, E. Vigil, M. A. HernándezFenollosa, X. Domènech, and J. A. Ayllón, "New lowtemperature preparation method of the $\mathrm{TiO}_{2}$ porous photoelectrode for dye-sensitized solar cells using UV irradiation," Journal of Photochemistry and Photobiology A, vol. 175, no. 23, pp. 165-171, 2005.

[21] T. N. Murakami, Y. Kijitori, N. Kawashima, and T. Miyasaka, "Low temperature preparation of mesoporous $\mathrm{TiO}_{2}$ films for efficient dye-sensitized photoelectrode by chemical vapor deposition combined with UV light irradiation," Journal of Photochemistry and Photobiology A, vol. 164, no. 1-3, pp. 187-191, 2004.

[22] N. Al Dahoudi, Wet chemical deposition of transparent conducting coatings made of redispersable crystalline ITO nanoparticles on glass and polymeric substrates [Ph.D. thesis], University of Saarland, Saarbrucken, Germany, 2003.

[23] I. Maksimenko, M. Gross, T. Königer, H. Münstedt, and P. J. Wellmann, "Conductivity and adhesion enhancement in lowtemperature processed indium tin oxide/polymer nanocomposites," Thin Solid Films, vol. 518, no. 10, pp. 2910-2915, 2010.

[24] N. Al Dahoudi, J. Xi, and G. Cao, "Silica modification of titania nanoparticles for dye-sensitized solar cell," Electrochemica Acta, vol. 59, pp. 32-38, 2012.
[25] T. P. Chou, Q. Zhang, B. Russo, G. E. Fryxell, and G. Cao, "Titania particle size effect on the overall performance of dyesensitized solar cells," Journal of Physical Chemistry C, vol. 111, no. 17, pp. 6296-6302, 2007.

[26] S. Sepeur, N. Kunze, B. Werner, and H. Schmidt, "UV curable hard coatings on plastics," Thin Solid Films, vol. 351, no. 1-2, pp. 216-219, 1999.

[27] E. Ukaji, T. Furusawa, M. Sato, and N. Suzuki, "The effect of surface modification with silane coupling agent on suppressing the photo-catalytic activity of fine $\mathrm{TiO}_{2}$ particles as inorganic UV filter," Applied Surface Science, vol. 254, no. 2, pp. 563-569, 2007.

[28] J. Xi, N. Al Dahoudi, Q. Zhang, Y. Sun, and G. Cao, "Effect of annealing temperature on the performances and electrochemical properties of $\mathrm{TiO}_{2}$ dye-sensitized solar cells," Science of Advanced Materials, vol. 4, no. 7, pp. 727-733, 2012.

[29] T. V. Nguyen, H. C. Lee, M. Alam Khan, and O. B. Yang, "Electrodeposition of $\mathrm{TiO}_{2} / \mathrm{SiO}_{2}$ nanocomposite for dye-sensitized solar cell," Solar Energy, vol. 81, no. 4, pp. 529-534, 2007.

[30] Q. A. Acton, Alloys: Advances in Research and Applications, Scholarly Edition, Atlanta, Ga, USA, 2011.

[31] G. Philipp and H. Schmidt, "The reactivity of $\mathrm{TiO}_{2}$ and $\mathrm{ZrO}_{2}$ in organically modified silicates," Journal of Non-Crystalline Solids, vol. 82, no. 1-3, pp. 31-36, 1986.

[32] N. Serpone and E. Pelizzetti, Photocatalysis: Fundamentals and Applications, Wiley, New York, NY, USA, 1989.

[33] M. R. Hoffmann, S. T. Martin, W. Choi, and D. W. Bahnemann, "Environmental applications of semiconductor photocatalysis," Chemical Reviews, vol. 95, no. 1, pp. 69-96, 1995.

[34] J. Van De Lagemaat, N. G. Park, and A. J. Frank, "Influence of electrical potential distribution, charge transport, and recombination on the photopotential and photocurrent conversion efficiency of dye-sensitized nanocrystalline $\mathrm{TiO}_{2}$ solar cells: a study by electrical impedance and optical modulation techniques," Journal of Physical Chemistry B, vol. 104, no. 9, pp. 2044-2052, 2000.

[35] Q. Wang, J. E. Moser, and M. Grätzel, "Electrochemical impedance spectroscopic analysis of dye-sensitized solar cells," Journal of Physical Chemistry B, vol. 109, no. 31, pp. 14945-14953, 2005.

[36] G. Schlichthörl, S. Y. Huang, J. Sprague, and A. J. Frank, "Band edge movement and recombination kinetics in dye-sensitized nanocrystalline $\mathrm{TiO}_{2}$ solar cells: a study by intensity modulated photovoltage spectroscopy," Journal of Physical Chemistry B, vol. 101, no. 41, pp. 8141-8155, 1997. 


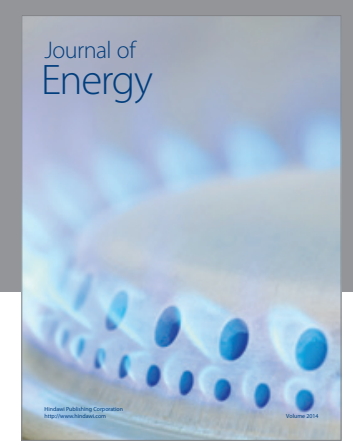

Journal of

Industrial Engineering
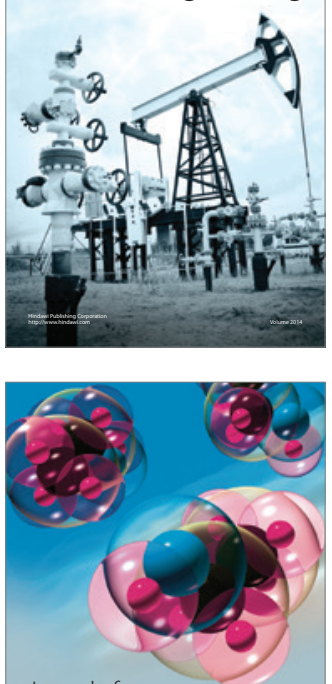

Fuels
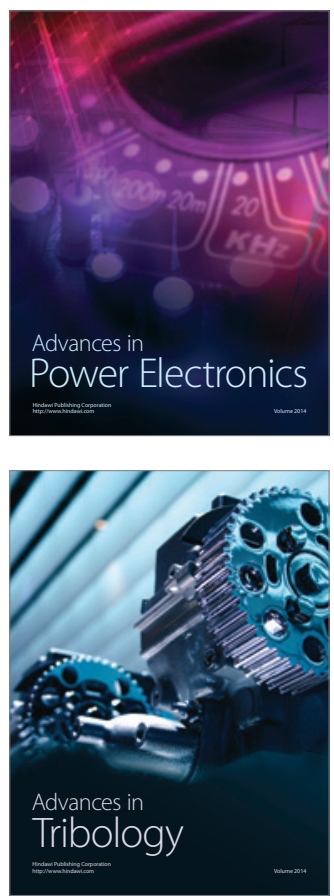

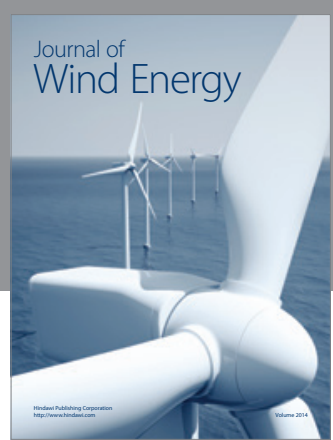

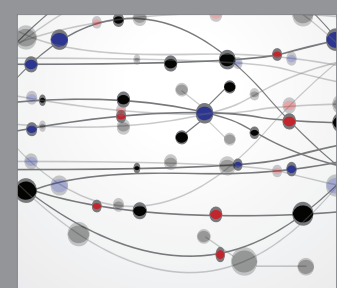

The Scientific World Journal

Submit your manuscripts at http://www.hindawi.com

Journal of

Structures
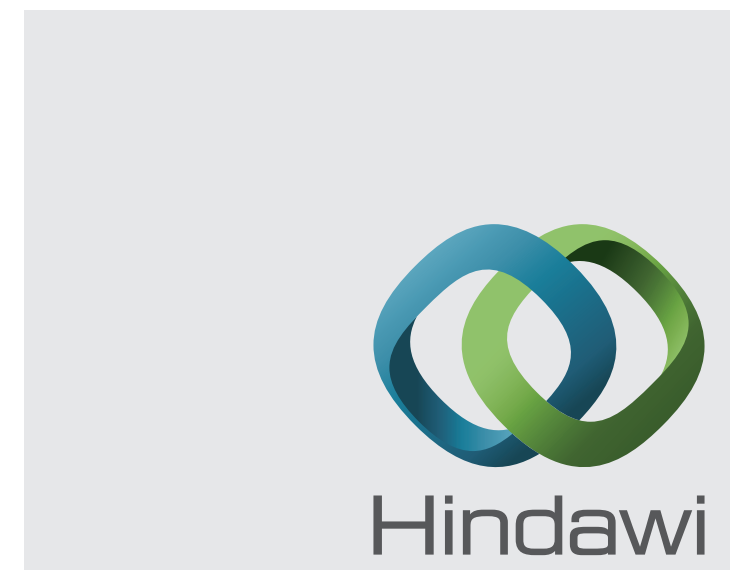

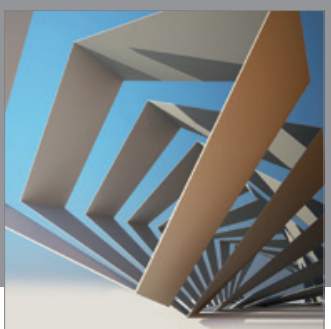

Rotating

Machinery
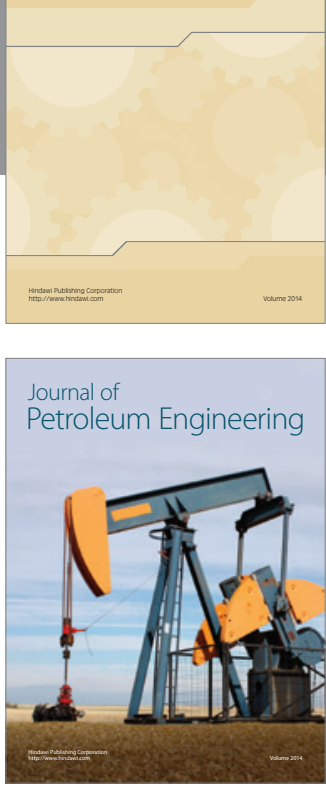

Journal of

Solar Energy
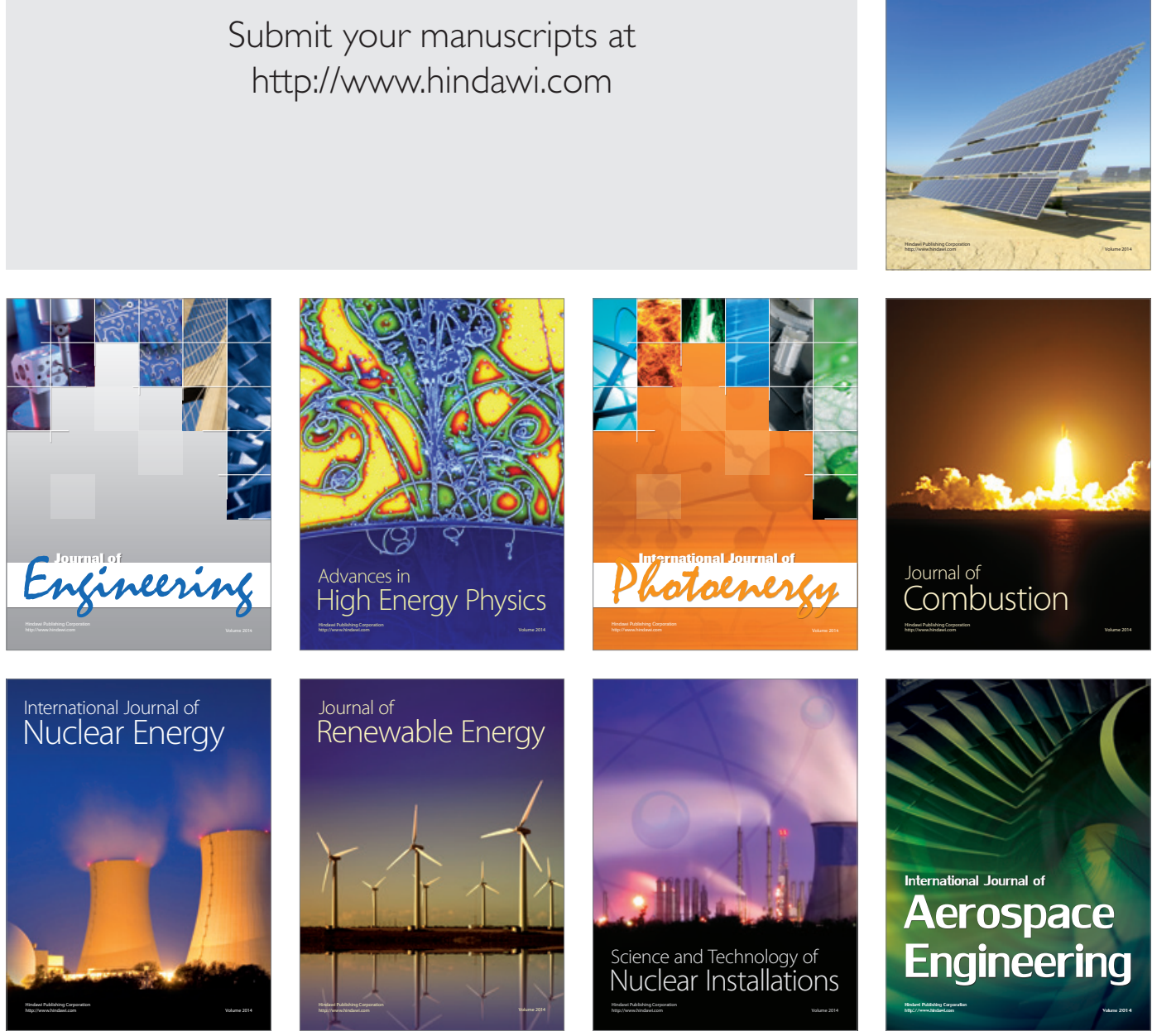